\title{
Idea de la poesía
}

\author{
VILARIÑO, Idea (2018). \\ De la poesía y los poetas. Recopilación y prólogo de Ana Inés Larre Borges. \\ Montevideo: Biblioteca Artigas, Ministerio de Educación y Cultura.
}

\section{Gustavo Lespada}

\section{ILH - UBA}

"Al medir a los poetas, Idea Vilariño descubre la poesía”, nos dice en su prólogo Ana Inés Larre Borges -albacea, custodia fiel de su obra-, porque "Idea no escribe ni para el público, ni para los poetas, ni para sí, escribe para la poesía o, mejor, por la poesía". Esta aguda síntesis de la compiladora nos da una idea de la importancia de haber recobrado y reunido en un volumen los dispersos escritos teóricos y críticos de esta enorme poeta uruguaya. Porque, efectivamente, Idea Vilariño (1920-2009) en forma paralela a su producción lírica escribió reseñas, artículos y ensayos, y en el despliegue analítico de estos textos, como una filigrana, se encuentra bordada, superpuesta su propia poética. Escribió sobre Rubén Darío, Julio Herrera y Reissig, Delmira Agustini, Jules Laforgue, Clara Silva, Juan Cunha, Antonio Machado, Parra del Riego, Baldomero Fernández Moreno, Paul Éluard, Pablo Neruda, Juan Ramón Jiménez, Pedro Salinas, Vicente Aleixandre, Nicanor Parra y Juan Gelman, entre otros. Además, resultan muy interesantes sus agudas reflexiones sobre el ritmo a partir de conceptos de T. S. Eliot y del menos conocido Pius Servien Coculesco, poeta y científico rumano-francés. Al erudito y riguroso ensayo que lo prologa -cuyo sugestivo título hemos tomado para esta reseña-, al trabajo encomiable de recopilación del material y al criterio en la elección y distribución de los textos cabe agregar el cuidado y la profesionalidad de una edición del más alto nivel académico.

Idea comparte la formulación de Eliot acerca de que un poema puede originarse a partir de un ritmo determinado antes de lograr su expresión en palabras, y así lo expresa, categóricamente, conversando con Mario Benedetti: "En un poema puede faltar todo lo demás; hasta puede, en determinados juegos, faltar el sentido; nunca el ritmo. Es esencial: por él algo es o no es lírico". De esta filiación eliotiana de Idea también proviene el título que se ha elegido para la antología-Eliot publica On poetry and poets en 1957, libro que reúne sus conferencias sobre poesía-. La notoria admiración por la poeta no le impide a Larre Borges señalar aquello que puede percibirse como un problema, como ser la reticencia de Vilariño hacia la llamada "poesía femenina" o las cuestiones de género, aventurando una hipótesis plausible sobre su origen: la resistencia de Idea hacia las determinaciones externas o las contingencias coyunturales sobre la creación poética. Esta defensa a ultranza de la autonomía del artista coincide con la proclamada por el peruano César Vallejo, sin que ello implicara falta de compromiso, sino todo lo contrario.

Suelo estar de acuerdo en que la biografía entorpece (condiciona, confunde) el análisis crítico -es frecuente encontrar ese determinismo reductor entre la vida y la obra en artículos y ensayos- pero, como toda norma, tiene sus excepciones. Y aquí, Larre Borges nos brinda una: la referencia introductoria acerca de la relación de Idea con su padre, Leandro Vilariño, no sólo nos ilustra sobre su temprano descubrimiento de la trascendencia del ritmo en la lírica -motivo central de sus reflexiones teóricas- sino que nos revela el origen filial de esa intensidad afectiva, entrañable, con la que siempre sintió y vivió la poesía. Como le respondiera a Elena Poniatowska, flaubertianamente: "La poesía es para mí una forma de ser, de mi ser. Todo lo demás en mi vida son accidentes. [...]. La poesía no fue accidental. Mi poesía soy yo". Perfecta definición de esa admirable convergencia entre el cuidado de la forma y la pasión visceral que la caracteriza. Idea, como nadie, encarnó el mandato de Darío: "Ama tu ritmo y ritma tus acciones". No es casual que Ángel Rama le encargara el ensayo "definitivo" que abre el volumen de la Biblioteca Ayacucho sobre Herrera y Reissig, el cual inicia también esta antología -junto con otros seis artículos que escribió sobre el admirado maestro.

Idea destaca que Herrera "optó por las más difíciles imposiciones: el soneto tenso y poblado; la décima sin resquicios, la rima perfecta y rara, llevada hasta tal extremo que a veces abarca el verso entero" y que, pese a su elogio de la "revolución decadentista" considera que él no es un decadente porque aunque le atraigan los esplines y las neurastenias nada en él es artificioso sino que "su entrega a la poesía es apasionada y avasallante", y que en su registro se instala, además de la herencia simbolista y del "vocabulario propio -por no decir exclusivo-, la adjetivación intrépida, la desmedida hipérbole, el violento oxímoron, el juego de lo abstracto y lo concreto". Idea incorpora y 
continúa las reflexiones de Herrera: “¿Cuántas facetas tiene el vocablo?". Asistimos a la puesta en valor de un poeta sobre otro, a la expansión del trabajo lírico insomne, a la disección de las "almas" de las palabras y sus ritmos porque, concluye: "todo es idea y todo es signo". Con varios ejemplos fundamenta el principio de confundir la palabra con la idea en una armónica amalgama; de alguna manera el concepto blanchotiano sobre que la forma significa ya estaba en el uruguayo. Respecto de su vertiente experimental-sostiene que es mucho más que un modernista-, Idea comprueba que Herrera ya había propuesto el "cataclismo de la gramática" que Vicente Huidobro reclamara en su Altazor III, en 1918.

A su vez, analizando La torre de las esfinges y anticipándose a la llamada Crítica Genética, trabaja con los manuscritos facsimilares de Herrera (reproducidos en el texto), sobre sus tachaduras y correcciones, desbrozando cada término, sopesando cada sonido hasta llegar a la versión definitiva. Como la honestidad intelectual de Idea no le permite ser complaciente, con su franqueza implacable es capaz de deconstruir una figura -"senos como lagos"- que la segunda versión, a su entender, ha malogrado, destinándola al fracaso "en la imaginación de cada lector". Y se trata de Herrera y Reissig, quien junto con Darío es uno de los poetas que más admira y de cuya obra llegará a decir que es "un hito en la poesía uruguaya, un punto a partir del cual no se podrá ya retroceder impunemente". Por eso, nuevamente, volviendo a la sabia conclusión del prólogo, cuando Idea lee a Herrera se lee; cuando busca el meollo, la secreta raíz de la creación del otro, se encuentra a sí misma: "Sobre el papel se realiza la ensañada partida: se cambian las piezas, se equilibra, se equidista, se pondera. Exigen los ritmos, la rima exige, la voz quiere decirlo mejor, más invenciblemente".

Solamente sus escritos sobre Herrera justifican un libro. Se ha dicho que los textos críticos de Vilariño son conversaciones entre pares, pero también hay en ellos mucha teoría propia entretejida con el estudio particular y minucioso. "Julio Herrera y Reissig. Seis años de poesía”, publicado en 1950 en la revista Número, constituye, a mi entender, uno de los ensayos más lúcidos que se hayan escrito sobre el poeta: cumple en insertar su poesía en la historia de la literatura continental a la vez que da cuenta de sus fuentes y lo compara con la producción contemporánea y con la tradición lírica. Analiza formalmente, de manera exhaustiva, las figuras, la métrica, el vocabulario, el timbre, temas e ideas, estilos y estructuras a lo largo de toda su obra; pero además, con ejemplar generosidad intelectual cita, dialoga, discute con toda la crítica literaria precedente que la poesía de Herrera ha suscitado y lo hace desde la fragua, desde la cocina, desde el conocimiento cabal del propio trabajo del poeta.

Tampoco tienen desperdicio los dos artículos sobre la poesía de Delmira Agustini: "una poesía del cuerpo, pero del cuerpo como campo agónico de lo erótico". Idea desentraña y formula la idea de Delmira "de llegar al alma por el cuerpo, de que la posesión física, aún en la forma primera del beso, permite la posesión total y más profunda del otro". Percibe y desarrolla su estrategia de apropiación de motivos y figuras modernistas para cambiarles el signo -sobre todo en Los cálices vacíos-, como hace en "El cisne", al invertir el sentido patriarcal del mito de Leda o transformando una alegoría en "el colmo de lo erótico"; y a partir del poema "Visión" describe cómo el ensueño, la imprecisión entre el sueño y la vigilia hacen posible una ambigüedad que se traduce en mayor libertad expresiva. De esta forma Idea sostiene que Delmira, mediante la plasticidad de una imagen polisémica, "Ilega a dar expresión tanto a lo inefable como a todo aquello que los tabúes sociales, familiares y literarios hubieran prohibido expresar". Poseedora de una potente herencia romántica y simbolista, la conjunción del amor y la muerte -que en Delmira toma el semblante del presagio- imprime a su poesía una "fuerza incontenible de los sentimientos [que] desborda los moldes" y en la búsqueda de expresar fielmente las emociones "arrasa con los juguetes modernistas y hace estallar las formas y el lenguaje". Por otro lado, Idea no acepta el mito de la espontaneidad y falta de meditación de su escritura; las abundantes correcciones y versiones de los cuadernos manuscritos de Delmira le darán la razón. ${ }^{1}$

Idéntica penetración y rigurosidad pondrá en los análisis críticos de la poesía de Jules Laforgue, de Dámaso Alonso, de Clara Silva, de Juan Cunha, de Parra del Riego, de Juan Ramón Jiménez, de Baldomero Fernández Moreno o Pablo Neruda. Aun en la reseña rápida y acotada de un poemario de amor como Los versos del capitán es capaz de extraer del entorno profuso la perla inmaculada de prepotente pasión: "Yo echo la puerta abajo: / yo entro en toda tu vida: / vengo a vivir en tu alma: / tú no puedes conmigo". Pero entre sus textos sorprende el estudio dedicado al método teórico de Pius Servien -cuyas investigaciones sobre el lenguaje poético son contemporáneas de los formalistas rusos-, que pretendía alcanzar formulaciones sobre el ritmo lírico expresadas en notaciones numéricas, es

\footnotetext{
1 Véase el documentado estudio de Carina Blixen, “Gestación de Los cálices vacíos”, en Delmira Agustini en sus papeles, Montevideo, Biblioteca Nacional Ministerio de Educación y Cultura, 2014, pp. 107-141.
} 
decir, en lenguaje matemático. La ciencia de la poesía, admite Idea, no podrá hacer poesía, "pero sí conocerla hasta donde sea posible", y esta fue una de sus constantes preocupaciones, sobre todo en lo que al ritmo concierne.

Hay veces que sus juicios resultan duros, durísimos, pero nunca hay malicia ni segundas intenciones en ellos sino una honestidad absoluta, íntegra, descarnada: dice lo que piensa sin ambages ni tapujos. Disecciona, pondera, mensura la materia poética de los otros como si fuera la propia porque su compromiso es incondicional, pero con la Poesía. Así, se permite disentir con la opinión laudatoria de Dámaso Alonso sobre Sombra del Paraíso de Vicente Aleixandre, y a la "fácil hermosura" de aquel libro -recrimina Vilariño al autor de Espadas como labios- le sigue la "acusada falta de rigor, de contención" de Nacimiento último (1953), al que tilda de estar falto de unidad y de ser una "vistosa e insatisfactoria mezcla de encanto y debilidad, con su 'ebrios de luz' imperdonable, sus adjetivos fáciles, su aparato paisajista, su retórica de invocaciones e imperativos". Y lo dice con pesar, porque considera que Aleixandre ha escrito "algunos de los más hermosos poemas [...] o, tal vez, algunos de los mejores versos de la lengua". Al final sugiere una perniciosa influencia nerudiana pero no omite dar cuenta de esos chispazos, de esos relámpagos donde aún se vislumbra al autor de La destrucción o el amor, aquella "antigua intensidad, el fiero destello apasionado que se estrella hermosamente en palabras".

Se trata de la Idea que desmigaja el componente místico de Animal de fondo (1949) de su admirado Juan Ramón Jiménez, para concluir que allí se trata de "un dios nuevo, no asimilable a ninguno de los habituales [...] un dios hecho con él", capaz de responder a todas las preguntas anteriores, como las del poema “Espacio” (1941-1942): “... el fondo del amor, / el horizonte que no quita nada, / la transparencia, dios, la transparencia". La misma Idea que no se deja espantar por la antipoesía de Nicanor Parra porque, afirma, "no hay nada en sus versos que no anduvieran haciendo hace veinte años los poetas de vanguardia", ni se deja engañar por sus clisés surrealistas ni sus golpes bajos, pero así como ve la cáscara también va al hueso: puede leer y valorar aquellos versos de Nicanor "que lo venden y desnudan la honda vena de su lirismo".
Este libro tiene una cima: un texto sobre el Gelman de Interrupciones I y II. Una cima o, mejor, un abismo: "es difícil leer estos poemas, padecerlos, tolerarlos", es difícil sin duda, pero sabemos con Lezama Lima que lo difícil es estimulante. Idea, en carne viva, lee estos "versos de belleza suma, llenando de sí líneas de otros, cosas del tango, perdiendo respeto a la sintaxis, a las concordancias, a las desinencias, a lo que sea, para que los versos digan lo que quiere decir", porque respetar las normas de una escritura "prolija" implicaría alguna forma de eufemismo o complicidad: el lenguaje también se encuentra devastado como el idioma alemán después del nazismo. Idea, conmovida, no puede dejar de citar a Gelman una y otra vez, pero no necesita reponer los hechos aberrantes porque allí están cifrados: "la memoria lo arroja en una marea desgarradora, en una feroz ola de odio y rabia contra la destrucción de tanto que fue amor". Idea abraza al que escribe partido entre los opuestos y las ausencias: "no quiero otra noticia sino vos / cualquier otra es migaja donde / se muere de hambre la memoria". Y de poeta a poeta, concluye: "Digo aquí que ha de ser difícil acercarse a otro libro más lleno de tristeza, de belleza y de amor".

Estamos ante una lectura sensible, figurada, poética sobre la poesía, una lectura que suma, que enaltece -aún cuando deshoja o desversa-, una lectura que amasa con la harina del poeta, que se calienta las manos sin temor a que el pan en la puerta del horno se le queme, una lectura que nos conecta visceralmente con todo lo inefable del lenguaje y que la poesía no puede dejar de acosar porque solo los zonzos no saben que de lo inasible no se escapa. Descubrir esta lectura crítica sensitiva, elaborada a espaldas de los aparatos teóricos, es como abrir una ventana y renovar el aire saturado de "artefactos", "aplicaciones" y "modelos" para conectarnos de otra manera con la palabra. Por todo ello recomendamos su lectura y concluimos esta presentación con las propias palabras de Idea Vilariño, las que eligió para cerrar su Poesía completa:

“Inútil decir más / nombrar alcanza”.

Buenos Aires, febrero de 2020 